\title{
Perflenapent Emulsion
}

National Cancer Institute

\section{Source}

National Cancer Institute. Perflenapent Emulsion. NCI Thesaurus. Code C116804.

An oil-in-water nano-emulsion composed of the perfluorocarbon perflenapent, that has oxygen-carrying capacity, can be used as a contrast agent and has potential antihypoxic and radiosensitizing activities. Upon intravenous administration of the perflenapent emulsion, this agent increases the oxygen-carrying capacity of blood, enhances the transport of oxygen to hypoxic and ischemic tissues and increases the oxygen concentration in these tissues. Hypoxic tumors are correlated with increased resistance to radiation treatment; therefore, since perflenapent may increase tumor oxygenation, it may improve the tumor's sensitivity to radiation therapy. 